\title{
Yellow cow Dung Powder- (Auramine Poisoning) - Study of Clinical Profile, And Statregies of Management
}

\author{
Dr.A.Muruganathan,M.D ${ }^{1}$,Dr.M.Venkatesh,M.D ${ }^{2}$. Dr.T.Ravikumar, M.D ${ }^{3}$., \\ Dr.S.Angayarkanni,M.D ${ }^{4}$, Dr.P.Saravanan,M.D. ${ }^{5}$ dr.Sopna Jothi,M.D., \\ ${ }^{I}$ Emeritus Professor The Tamil Nadu Dr.MGR Medical University \\ ${ }^{2}$ Asst Prof of medicine Govt Theni Medical College, Theni \\ ${ }^{3}$ Prof and Hod of Medicine Govt.Medical College AndEsi Hospital, Coimbatore \\ ${ }^{4}$ Asst professor of forensic MedicineGovt.Medical College AndEsi Hospital, Coimbatore \\ ${ }^{5}$ Asst Prof of MedicineMadurai Medical College,Madurai \\ ${ }^{6}$ Asst Profof Medicine Govt Theni Medical College, Theni
}

\begin{abstract}
:
Introduction; Auromine is a florescent yellow, tasteless, odour less, water soluble highly lethal, easily available household poison which kills about thousands of people in Coimbatore, Tiruppur and Erode districts and southern parts of Tamilnadu

Aim of the study; This is a prospective study to analyze the clinical presentations ,symptoms, signs, biochemical changes in patients with yellow cow dung powder poisoning, and strategies of management as there is no protocol of management available except symptomatic treatment and it is highly toxic, Only Few Case Studies Are Published And No Detailed Research Papers Available

Materials and methods; All the patients admitted in Govt Medical College hospitals with history of alleged YELLOW cow dung powder poisoning are taken for study .those patients with pre existing liver diseases are excluded from this study

Results; of the 1183 no of patients studied many $23 \%$ of them exhibited signs of liver cell failure, $28 \%$ bleeding manifestations, 43\%neurological manifestations 6\% had other complication, Conclusion; early gastric lavage, in conscious patients, followed by continuous ryles tube aspiration washing the skin and eyes, symptomatic treatment for hepatitis prevention of hepatic encephalopathy, convulsions and ventilator support for patients with respiratory failure, treatment of arrhythmias are the main treatments
\end{abstract}

Keywords: Yellow Cow Dung Powder,- Saani Powder, Auramine O- Yellow Dye -Poisoning

\section{Introduction}

Auramine is a florescent yellow, tasteless, odour less, water soluble highly lethal, easily available household poison which kills about thousands of people in Coimbatore, Tiruppur and Erode districts and southern parts of Tamilnadu There are very few articles in literature regarding this poisoning. Hence, the mechanism of action, clinical presentation, and cause of death is not clearly given in any text books

Auramine $\mathbf{O}$ is a diarylmethane dye used as a fluorescent stain. In its pure form, Auramine $\mathrm{O}$ appears as yellow needle crystals. It is very soluble in water and soluble in Ethanolalthough The Requirement For Metabolic Activation Regarding Auramine Is Unresolved, It Is Considered To Be A Pro-Carcinogen.

Mechanism of Action: It Possesses Methylated Amino Groups. It Will Undergo Resonance Conjugation Rendering The Amino N Atom Positively Charged \& Thus More Prone To Hydroxylation. The Direct Activity Of Auramine Variously Reported May Be Due To Weak Electrophilicity At The Un substituted Positively Charged Central N Atom In The Other Extreme Resonance Commercial Auramine O Was Positive In Inducing DNA Damage In Vivo In Liver, Kidney, \& Bone Marrow Cells

The Human Health Assessment Group in EPA's Office of Health and Environmental Assessment has evaluated auramine for carcinogenicity. According to their analysis, the weight-of-evidence for auramine is group B2, which is based on inadequate evidence in humans and sufficient evidence in animals. As a group B2 chemical, auramine is considered probably carcinogenic to humans.

DNA Damage Was Induced After Treatment In Vitro Of A Human Cell Line. Purified Auramine Was Negative Regarding Dna Damage \& Sister Chromatid Exchange Induction. Commercial Auramine Used In The Study Had Michlar's Ketone As A Major Contaminant

In occupational settings, worker exposure to auramine hydrochloride is expected to be via inhalation of dust and dermal contact. BUT IN MANY AREAS IT IS CONSUMED FOR SUICIDAL PURPOSES ONLY 
Yellow cow Dung Powder- (Auramine Poisoning) - Study of Clinical Profile, And Statregies of ....

As This is Easily Available In All Petty Shops As A Decorative Mixture For Applying In Front of the House Every Day Or At Least Weekly Twice On Tuesdays And Fridays As These Days Are Considered Auspicious. days

They Used To Mix It With Cow dung And Mix With Bare Hand Hence The absorption Through Skin, Can Produce STAIN ,Nausea And Vomiting, Since It Is A Basic Dye Its Stain Remain For Two To Three Days Easily Available Cheap Poison All It Takes To Kill Is Rs 5/-As The Lethal Dose Is .5mg /Kg Body Weight Hence It Is Considered As House Hold Poison And Children Accidentally Consumes And Get Admit Frequently There are very few articles in literature regarding this common household poisoning. hence, the mechanism of action, clinical presentation, and cause of death is not clearly written in any text books of medicine or toxicology

There is no specific antidote for these dyes. Deaths had occurred within hours of ingestion in several instances. Over half the deaths in the first day DUE TO CEREBRAL OEDEMA(the dye stains the brain and CSF, as it crosses the blood brain barrier ), resulting in convulsions, ,coma respiratory and cardiac arrest ,death. If the patient survives, in the day two to three following which liver damage, the direct action of dye causes centri lobar necrosis, resulting in hepatitis, fulminent hepatic failure hepatic encephalopathy, bleeding and death

In the first stage [<24 hours], patient is either asymptomatic or has signs and symptoms of local gastrointestinal irritation with. Diarrhea, The second stage [24-72 hours] after ingestion is also an asymptomatic period but mild biochemical alteration in liver functions may be found. The third stage advanced occurs beyond 72 hours until the resolution of symptoms or death. and symptoms of local gastrointestinal irritation

Materials and methods Patients admitted with consumption of cow dung powder ( chemical dyes) in general medicine department of various Govt. Medical colleges in southern Tamilnadu were analysed during January 2014 to April 2017.Results; Total number of patient studied were 1183 and 978 survived and 205 deaths were recorded in ours study . common symptomatolgy is represented in the table Clinical signs and symptoms; Staining all over the body especially hands face and tongueNausea, vomiting, hemetemesis, melena, hematuria, high coloured urine,epigastric tenderness abdominal pain, tenesmus , cramps, diarrhea,Purpuric spots ,haemorrage, Confusion, Irritability, flopping tremors, stupor, convulsion, coma Bio chemical abnormalities,SGOT, SGPT, Serum bilirubin, elevatedAbnormal bleeding time and clotting time, apttsecond day to third day patient may develop signs of liver cell failure

\begin{tabular}{|l|l|l|}
\hline s.no & Symptoms and signs & Numbers ( percentage) \\
\hline 1 & Altererd conscious /coma & $685(57.9)$ \\
\hline 2 & Seizures & $367(31)$ \\
\hline 3 & Tachycardia & $984(83)$ \\
\hline 4 & Tachypnea & $1103(93.2)$ \\
\hline 5 & Required ventilator support & $678(57.3)$ \\
\hline 6 & hypotension & $653(55.1)$ \\
\hline 7 & Jaundice & $743(62.8)$ \\
\hline 8 & Oliguria & $456(38.5)$ \\
\hline 9 & vomiting & $987(83.4)$ \\
\hline 10 & asymptomatic & $134(11.3)$ \\
\hline
\end{tabular}


Yellow cow Dung Powder- (Auramine Poisoning) - Study of Clinical Profile, And Statregies of ....

Prognosis;depends up on ;the quantity of poison taken in empty stomach, ,delay in treatment initiation, associated co morbidities. The average hospital stay was from 5 to 12 days. Most of them recovered with out sequele. Investigations on admission such as complete haemogram to rule out, renal function test (RFT), serum electrolytes, and coagulation profile to be tested. Liver function tests to be repeated often , bleeding time and clotting time, frequent blood sugar level monitoring are mandatory, diarrhoea, convulsion and coma are bad prognostic signs during admission

Management; There is no specific antidote for these dyes, Supportive therapy is the mainstay of treatment stomach wash with plain water in conscious patients in unconscious continuous ryles tube aspiration advised and. Activated charcoal is useful in most cases for reducing the absorption from GIT

Anti emetics, proton pump inhibitors, vit $\mathrm{K}$ in bleeding diathesis, fresh frozen plasma, blood transfusion rarely required,Anti epileptics in convulsions,mannital, 20\% in cerebral oedema, management of livercell failure with ursodeoxycholic acid and metadoxineare $\mathrm{N}$-acetyl cystiene Albumin,employed in certain patients in response to demanding clinical situation. some required ventilatory support

\section{discussion}

Krishnamoorthyet al. in his retrospective analysis of cow dung powder poisoning had just listed the number of patients developing various system involvements. However, the clinical presentation and biochemical abnormalities were not discussed.

Auramine causes centrilobular necrosis of liver. It is also a gastrointestinal tract irritant causing mucosal damage, epigastric pain, and discomfort. Many ofour patients had consumed had features of toxic hepatitis from day three of poison intake. In many patients, SGOT and SGPT levels were elevated, but bilirubin levels and coagulation parameters were normal.initially. In contrast, in some patients we observed that apart from SGOT and SGPT, bilirubin levels and coagulation parameters were also elevated.

Auramine is a neuro toxic poison which causes central nervous system (CNS) depression. Direct CNS effect of the poison is clearly evident from the low GCS of the patients ${ }^{\mathrm{I}}$ Tachycardia, metabolic acidosis, and hyperglycemia observed

Ursodeoxycholic acid was use ful in manypatients because in addition to its choleretic effect, it also has immunomodulatory and antiapoptotic properties. ${ }^{[5]}$ More studies are needed to determine the management of toxic hepatitis and the role of N-acetyl cysteine in auromin poisoning. Even though other organs looked unaffected in our cases, more number of patients should be studied before concluding.

Other studies also confirm DNA damage induced by auramine in liver, kidney, and bone marrow of rats and mice, and in human cell line. Eye contact of auramine can produce injuries such as conjunctivaledema, hyperemia, purulent discharge, and total opacification. Chronic health effects of auramine exposure are carcinogenic and mutagenic with higher incidence of bladder cancer, lymphatic cancer, and also cause reproductive damage in humans.

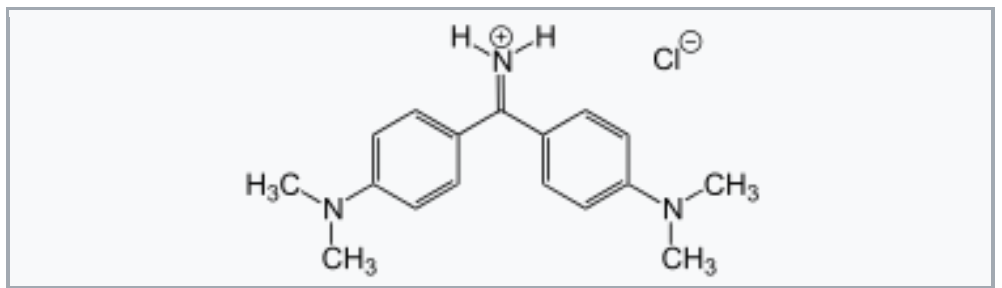




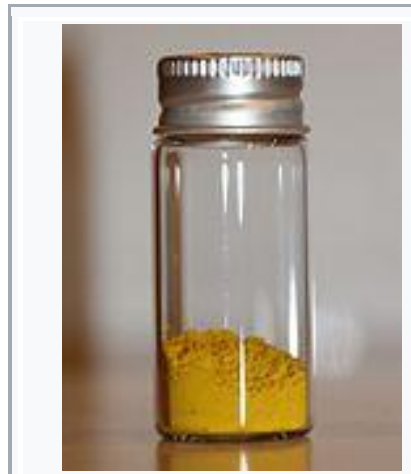

Solid Auramine O

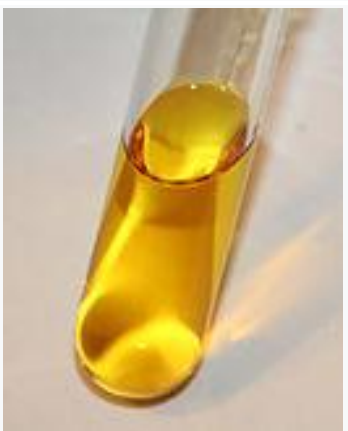

Auramine $\mathrm{O}$ in aqueous solution

\begin{tabular}{l}
\multicolumn{1}{c}{ Names } \\
\hline $\begin{array}{l}\text { IUPAC name } \\
\text { bis[4-(dimethylamino)phenyl]methaniminium chloride }\end{array}$ \\
\hline $\begin{array}{l}\text { Other names } \\
\text { auramine hydrochloride, basic yellow 2, pyocataniumaureum, } \\
\text { aizenauramine, pyoktanin yellow, canary yellow, pyoktanin, or C.I. } \\
41000\end{array}$
\end{tabular}

\begin{tabular}{|c|c|}
\hline \multicolumn{2}{|c|}{ Identifiers } \\
\hline CAS Number & 2465-27-2 \\
\hline 3D model ( $\underline{\mathrm{Jmol}})$ & $\begin{array}{l}\text { Interactive image } \\
\text { Interactive image }\end{array}$ \\
\hline ChemSpider & 16254 \\
\hline ECHA InfoCard & 100.017 .789 \\
\hline PubChem CID & $\underline{17170}$ \\
\hline \multicolumn{2}{|l|}{$\underline{\text { InChI[show] }}$} \\
\hline \multicolumn{2}{|l|}{$\underline{\text { SMILES[show] }}$} \\
\hline \multicolumn{2}{|c|}{ Properties } \\
\hline Chemical formula & $\mathrm{C}_{17} \mathrm{H}_{22} \mathrm{ClN}_{3}$ \\
\hline Molar mass & $303.83 \mathrm{~g} \cdot \mathrm{mol}^{-1}$ \\
\hline Melting point & $267^{\circ} \mathrm{C}\left(513^{\circ} \mathrm{F} ; 540 \mathrm{~K}\right)$ \\
\hline \multicolumn{2}{|r|}{ Hazards } \\
\hline$\underline{\text { R-phrases }}$ & $\underline{\mathrm{R} 22} \underline{\mathrm{R} 24} \underline{\mathrm{R} 40}$ \\
\hline S-phrases & $\underline{\mathrm{S} 36 / 37} \underline{\mathrm{S} 45}$ \\
\hline \multicolumn{2}{|c|}{$\begin{array}{l}\text { Except where otherwise noted, data are given for materials in } \\
\text { their standard state (at } 25^{\circ} \mathrm{C}\left[77^{\circ} \mathrm{F}\right], 100 \mathrm{kPa} \text { ). }\end{array}$} \\
\hline \multicolumn{2}{|c|}{$\sqrt{\text { verify }}($ what is $\boldsymbol{x}$ ?) } \\
\hline \multicolumn{2}{|c|}{$\underline{\text { Infobox references }}$} \\
\hline
\end{tabular}

Auramine $\mathbf{O}$ is a diarylmethane dye used as a fluorescent stain. In its pure form, Auramine O appears as yellow needle crystals. It is very soluble in water and soluble in ethanol.Auramine $O$ can be used to stain acidfast bacteria (e.g. Mycobacterium, where it binds to the mycolic acid in its cell wall) in a way similar to ZiehlNeelsen stain. ${ }^{[11}$ It can also be used as a fluorescent version of Schiff reagent. ${ }^{[2]}$ Auramine O can be used together with $\underline{\text { Rhodamine B }}$ as the Truant auramine-rhodamine stain for $\underline{\text { Mycobacterium tuberculosis. }} .{ }^{[3][4]}$ It can be also used as an antiseptic agent. 


\section{Laboratory:}

a) Monitor the patient carefully for clinical evidence of systemic toxicity or severe dermal reaction. Patients with no symptoms or minimal irritation generally do not require laboratory evaluation.

b) Monitor vital signs and mental status.

c) Test the $\mathrm{pH}$ of the product to assess for its ability to cause caustic injury.

d) Monitor serum electrolytes, renal function and hepatic enzymes in patients with very large dermal exposures or systemic symptoms.

e) Determine methemoglobin concentration in patients who are cyanotic or have clinical evidence of hypoxia.

f) Institute continuous cardiac monitoring and obtain an ECG in symptomatic patients.

g) Obtain a chest radiograph in patients with persistent cough, wheezing or respiratory distress.

\section{Treatment Overview:}

\section{"Symptomatic.}

\section{Eye Exposure}

Remove contact lenses and irrigate exposed eyes with copious amounts of room temperature $0.9 \%$ saline or water for at least 15 minutes. If irritation, pain, swelling, lacrimation, or photophobia persist after 15 minutes of irrigation, the patient should be seen in a healthcare facility.

\section{Dermal Exposure}

1) wash with copious amount of water Remove contaminated clothing, wash exposed skin thoroughly with soap and water, and irrigate exposed eyes.

2) Support; Most patients will do well with supportive care. Monitor vital signs and mental status. Treat hypotension with intravenous fluids, add vasopressors, f hypotension persists. Arrange for early (ideally within 24 hours) endoscopy for patients with concern for caustic GI injury. Treat bronchospasm with inhaled beta agonists and corticosteroids. Endotracheal intubation and mechanical ventilation may be needed in patients with significant CNS depression or respiratory distress.

\section{Physical Examination}

a) Perform serial examinations to determine whether the patient is improving or deteriorating. Perform a slit lamp exam and evaluate visual acuity in any patient with an eye exposure.

Hypotension: Infuse 10 to $20 \mathrm{~mL} / \mathrm{kg}$ isotonic fluid. If hypotension persists, administer dopamine (5 to 20 $\mathrm{mcg} / \mathrm{kg} / \mathrm{min}$ ) or norepinephrine (ADULT: begin infusion at 0.5 to $1 \mathrm{mcg} / \mathrm{min}$; CHILD: begin infusion at 0.1 $\mathrm{mcg} / \mathrm{kg} / \mathrm{min})$; titrate to desired response.

Ventricular Dysrhythmias/Summary: Institute continuous cardiac monitoring, obtain an ECG, and administer oxygen. Evaluate for hypoxia, acidosis, and electrolyte disorders. Lidocaine and amiodarone are generally first line agents for stable monomorphic ventricular tachycardia, particularly in patients with underlying impaired cardiac function. Amiodarone should be used with caution if a substance that prolongs the QT interval and/or causes torsades de pointes is involved in the overdose. Unstable rhythms require immediate cardioversion.

Seizures: Administer a benzodiazepine; DIAZEPAM (ADULT: 5 to $10 \mathrm{mg}$ IV initially; repeat every 5 to 20 minutes as needed. CHILD: 0.1 to $0.5 \mathrm{mg} / \mathrm{kg}$ IV over 2 to 5 minutes; up to a maximum of $10 \mathrm{mg} / \mathrm{dose}$. May repeat dose every 5 to 10 minutes as needed) or LORAZEPAM (ADULT: 2 to $4 \mathrm{mg}$ IV initially; repeat every 5 to 10 minutes as needed, if seizures persist. CHILD: 0.05 to $0.1 \mathrm{mg} / \mathrm{kg}$ IV over 2 to 5 minutes, up to a maximum of $4 \mathrm{mg} /$ dose; may repeat in 5 to 15 minutes as needed, if seizures continue).

1) Consider phenobarbital or propofol if seizures recur after diazepam $30 \mathrm{mg}$ (adults) or $10 \mathrm{mg}$ (children greater than 5 years).

2) Monitor for hypotension, dysrhythmias, respiratory depression, and need for endotracheal intubation. Evaluate for hypoglycemia, electrolyte disturbances, and hypoxia.

Coma Aggressively treat and evaluate coma regardless of suspected cause. Intubate and ventilate as needed. Comatose patients should receive oxygen, naloxone, thiamine (adults), and either D50 or rapid determination of blood glucose. Check core temperature to evaluate for hypo- or hyperthermia. Consider evaluation for CNS lesion or infection with CT scan and lumbar puncture.a)

\section{Patient Disposition}

a) Home Criteria: Patients who are asymptomatic or have minimal irritant symptoms after an inadvertent small dermal exposure can probably be observed at home.

b) Observation Criteria: Patients with systemic symptoms, those with large surface area exposures, or patients with more than minimal dermal or eye irritation should be referred to a healthcare facility for 6 to 8 hours of observation. 
Yellow cow Dung Powder- (Auramine Poisoning) - Study of Clinical Profile, And Statregies of ....

c) Admission Criteria: Patients with severe dermal or eye injury, persistent symptoms or laboratory abnormalities should be admitted.

d) Consult Criteria: Consult a medical expert for any patient with symptoms or a large exposure.

a) Health care personnel should take precautions to avoid exposure to contaminated skin or clothing of the patient. Safety and health care personnel should refrain from entering a contaminated area in order to rescue or treat an individual unless appropriate protective equipment and rescue procedures are in use;

post mortem findings; all the organs, liver spleen kidneys, brain and csf stained yellow, gastric mucosa haemorragic spots seen

\section{References}

[1]. Hisham MD, Vijayakumar A, Rajesh N, Sivakumar MN. Auramine-o and malachite green poisoning: Rare and fatal. Indian J Pharm Pract 2013;6:72-4.

[2]. Singh UK, Layland FC, Prasad R, Singh S. Miscellaneous: Poisoning in Children. 3 rd ed. New Delhi: Jaypee Publishers; 2006. p. 213-15.

[3]. Karikalan T, Murugan M. Profile of poisoning cases in a tertiary care hospital, Tamil Nadu. J Evol Med Dent Sci 2014;3:12754-60.

[4]. Krishnamoorthy A, Subramanian R, Dhanaselvi P, Prabhu RS, Jayanthi V. Clinical presentation of cow dung powder poison - A preliminary communication. J Assoc Physicians India 2001;49.

[5]. Angulo P. Use of ursodeoxycholic acid in patients with liver disease. CurrGastroenterol Rep 2002;4:37-44.

[6]. Parodi S, Santi L, Russo P, Albini A, Vecchio D, Pala M, et al. DNA damage induced by Auramine O in liver, kidney, and bone marrow of rats and mice, and in a human cell line (Alkaline elution assay and SCE induction). J Toxicol Environ Health 1982; 9:941-52. [PUBMED]

[7]. [IARC. Monographs on the Evaluation of the Carcinogenic Risk of Chemicals to Humans. Geneva: World Health Organization, International Agency for Research on Cancer, 1972-PRESENT. (Multivolume work). Available at: http://monographs.iarc.fr/ENG/Classification/index.php p. S7 118 (1987)] **PEER REVIEWED*

[8]. Sherfudeen KM, Kaliannan SK, Dammalapati PK. Cow dung powder poisoning. Indian J Crit Care Med 2015;19:684-6 http://www.ijccm.org/text.asp?2015/19/11/684/169357. /Auramine/ [Parodi S Et Al; J Toxicol Environ Health 9 (5-6): 941 (1982)]।

[9]. Thanks to Prof. Dr. Edwin joe.M.D.B.L Director of Medical Education, Govt of Tamilnadu India 